\title{
Inclusion of clavulanic acid determinants in the basophil activation test improves the evaluation of immediate reactions to amoxicillin-clavulanic acid
}

\author{
Tahia D Fernandez ${ }^{1 *}$, Adriana Ariza $^{2}$, Maria Salas $^{3}$, Maria I Montañez ${ }^{1}$, Inmaculada Doña ${ }^{3}$, Lidia Melendez ${ }^{1}$ \\ Maria D Cañamero ${ }^{3}$, Miguel Blanca ${ }^{3}$, Maria J Torres ${ }^{3}$, Cristobalina Mayorga ${ }^{1}$ \\ From 6th Drug Hypersensitivity Meeting (DHM 6) \\ Bern, Switzerland. 9-12 April 2014
}

\section{Background}

The clavulanic acid (CLV) is nowadays frequently included in the treatment with Amoxicillin (AX). This component of the antibiotic therapy initially thought to have a low immunogenic capacity; however immediate allergic reactions to CLV have been reported in a $30 \%$ of patients allergic to AX-CLV. Basophil activation test (BAT) has shown promising results demonstrating specific recognition of CLV determinants. The aim of this study was to assess the value of BAT in the evaluation of immediate allergic reactions to CLV.

\section{Method}

Patients with a strong clinical history of having suffered an immediate reaction after AX-CLV administration were evaluated. The allergological study followed the European Academy guidelines, included skin test with penicillin G, AX, and CLV determinants and drug provocation test when indicated. BAT was carried out using $\mathrm{AX}$ and CLV at different concentrations $(2.5,1.25,0.25$ and $0.05 \mathrm{mg} / \mathrm{ml}$ ).

\section{Results}

Among 75 patients included, 64 were finally diagnosed as allergic, 26 to AX and 38 to CLV. The sensitivity of BAT was $60 \%$ and the specificity $81.8 \%$. The inclusion of AX determinant produced a BAT sensitivity of $54.1 \%$ whereas CLV determinant produced a BAT sensitivity of $78.6 \%$ with a specificity of $91 \%$ and $82 \%$ respectively. In patients diagnosed as allergic to AX the BAT sensitivity was $50 \%$

$\overline{1}$ IBIMA-Regional University Malaga Hospital-UMA, Research Laboratory, Spain Full list of author information is available at the end of the article whereas in patients allergic to CLV, BAT sensitivity was $65.8 \%$.

\section{Conclusion}

The inclusion of clavulanic acid in the basophil activation test increases its diagnostic capacity in patients with immediate allergic reaction to the combination amoxicillinclavulanic acid.

\section{Authors' details}

'IBIMA-Regional University Malaga Hospital-UMA, Research Laboratory, Spain. 2IBIMA-Regional University Malaga Hospital-UMA, Allergy Service, Spain.

${ }^{3}$ Regional University Malaga Hospital, Allergy Service, Spain.

Published: 18 July 2014

\section{doi:10.1186/2045-7022-4-S3-P32}

Cite this article as: Fernandez et al:: Inclusion of clavulanic acid

determinants in the basophil activation test improves the evaluation of

immediate reactions to amoxicillin-clavulanic acid. Clinical and Translational Allergy 2014 4(Suppl 3):P32.

Submit your next manuscript to BioMed Central and take full advantage of:

- Convenient online submission

- Thorough peer review

- No space constraints or color figure charges

- Immediate publication on acceptance

- Inclusion in PubMed, CAS, Scopus and Google Scholar

- Research which is freely available for redistribution 